Dear Author,

Please, note that changes made to the HTML content will be added to the article before publication, but are not reflected in this PDF.

Note also that this file should not be used for submitting corrections. 


\title{
Physical model tests and numerical simulation for assessing the stability of brick-lined tunnels
}

\author{
Han-Mei Chen ${ }^{a, *}$, Hai-Sui Yu ${ }^{a}$, Martin J. Smith ${ }^{b}$ \\ a Nottingham Centre for Geomechanics, The University of Nottingham, NG7 2RD, UK \\ ${ }^{\mathrm{b}}$ Nottingham Geospatial Institute, The University of Nottingham, NG7 2TU, UK
}

\section{A R T I C L E I N F O}

\section{Article history:}

Received 19 May 2015

Received in revised form 3 November 2015

Accepted 11 January 2016

Available online $\mathrm{xxxx}$

\section{Keywords:}

Physical models

Numerical simulation

Tunnel stability

Condition monitoring

Deformation

\begin{abstract}
A B S T R A C T
Nowadays, numerical modelling is increasingly used to assess the stability of tunnels and underground caverns. However, an analysis of the mechanical behaviour of existing brick-lined tunnels remains challenging due to the complex material components. In order to study the mechanical behaviour of the masonry in brick-lined tunnels, this paper reports a series of small scale physical tunnel model tests to represent the true behaviour of a real tunnel under extreme loading. Advanced monitoring techniques of laser scanning and photogrammetry are used to record tunnel deformation and lining defects. This investigation shows how these techniques may substitute or supplement the conventional monitoring procedures. Moreover, numerical analyses based on continuum and discontinuum approaches are carried out. The numerical results are compared with physical model tests to assess the overall stability of these tunnels. Predictions using numerical models under various conditions have also been carried out to show the mechanical behaviour of masonry tunnel and to quantify the influence of the boundary and loading conditions.
\end{abstract}

(c) 2016 Published by Elsevier Ltd.

\section{Introduction}

Most old tunnels in UK were built decades ago; some are even over a hundred years old. These ageing infrastructures pose significant risk to safety and efficiency of the infrastructure, which may have negative impact on the economy. Tunnels are usually lined with bricks or stones, which may suffer from material degradation and changing loading conditions after many years of service. Reliable assessment of stability of such tunnels is important for designing maintenance and refurbishment measures.

However, quantitative safety assessment is very difficult to undertake since many factors are unknown, for example the behaviour of construction materials and the underground conditions. Although several numerical models have been proposed to study the structural behaviour of masonry infrastructure, for example old tunnel masonry structures (Idris et al., 2008, 2009), masonry bridges (Betti et al., 2008), and masonry structures (Giordano et al., 2002; Lourenço, 1996, 1998; Sutcliffe, 2003; Valluzzi et al., 2005), the modelling and the mechanical behaviour analysis of existing brick-lined tunnels remains challenging due to the complex material components. The engineering practice of tunnel refurbishment is still largely dominated by ad-hoc stabilizing mea-

* Corresponding author.

E-mail addresses: hanmeichen0527@gmail.com (H.-M. Chen), hai-sui. yu@nottingham.ac.uk (H.-S. Yu), martin.smith@nottingham.ac.uk (M.J. Smith). sures based on experience. Tunnel monitoring has predominantly been a manual process, which is time-consuming and subjective, giving rise to variance in the standards and quality of examination.

To develop an understanding at the performance of brick-lined tunnels, the overall aim of this research is to develop a numerical approach for the modelling of a series of small scale physical model tunnels under extreme loading. The deformation of the brick-lined tunnels is assessed through both the physical test models and the numerical modelling.

During the physical model tests, advanced monitoring techniques of laser scanning and photogrammetry are used to record tunnel deformation and lining defects, which may substitute or supplement the conventional manual procedures. This is explained in Chen et al. $(2013,2014)$ and Chen (2014). Numerical models are developed to simulate the corresponding physical models; the results of the physical model tests are used as a base for the validation of numerical models. These numerical models and advanced monitoring techniques then have the potential to be applied to field studies to enable accurate prediction of the actual behaviour of real masonry tunnels, see Fig. 1.

As full compliance with scaling laws is often impossible, these small scale physical model tests are not required to closely replicate the real tunnel behaviour with its many and varied conditions, but should provide similar boundary and loading conditions, which can be controlled and measured. 


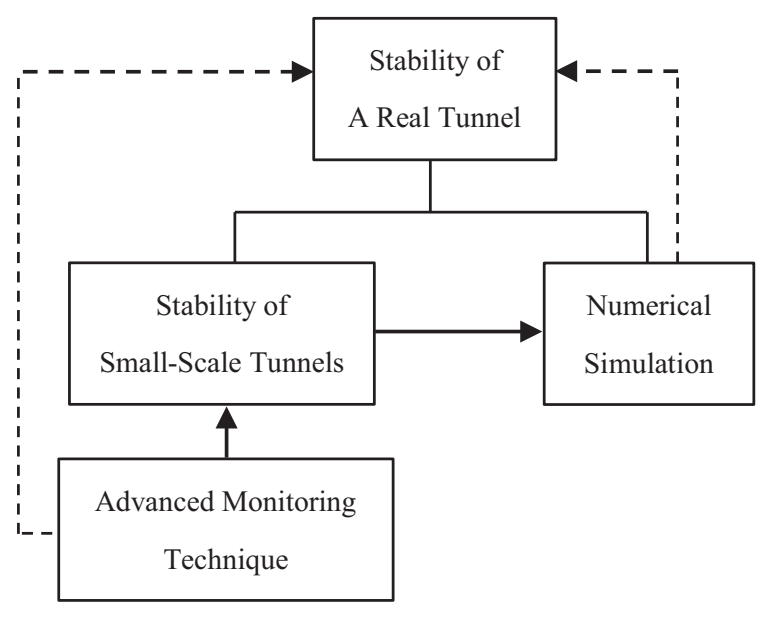

Fig. 1. The methodology of the overall research.

\section{Physical model preparation and test setup}

\subsection{Brief introduction}

Physical model testing in the laboratory is an invaluable procedure in masonry research to demonstrate the performance of real masonry structures. It is often advisable to undertake the testing of small scale physical models prior to field studies for safety and economic reasons.

In this study a series of large small scale physical tunnel models under normal gravity ( $1 \mathrm{~g}$ ) were built up in the laboratory to reproduce the phenomena, and to assess the stability of brick-lined railway tunnels and their mechanical behaviours under controlled conditions. In order to simulate the behaviour of both deep seated (e.g. mountain tunnels) and shallow brick-lined tunnels affected by traffic load, the physical model tests were subjected to static uniform and concentrated load applied to the surface of the overburden soil.

\subsection{Test variations}

Different from the construction of brickwork buildings nowadays, lime, cement and sand were usually used in the mortar mix to build old brick-lined tunnels. For the first physical model, a comparatively higher strength mortar mix comprising cement, lime and sand in respective proportions of ratio 1:1:6 as prescribed by with BS 4551:1980, 1980 was used. For both the second and the third physical model, a mortar mix proportion of lower strength $(1: 2: 9)$ was used. Table 1 shows the different combinations of variables investigated for the three physical model tests conducted.

\subsection{Model constructions}

The construction of all three physical models in this study followed an identical process to ensure consistency and comparability. The key elements of the construction process were the brickwork liner, rigid box, plastic sheeting, and surrounding soil.

Table 1

Loading outputs from three physical models.

\begin{tabular}{lll}
\hline Test number & Mortar mix proportion & Loading style \\
\hline Physical model test 1 & $1: 1: 6$ (higher strength) & Uniform load \\
Physical model test 2 & 1:2:9 (lower strength) & Uniform load \\
Physical model test 3 & 1:2:9 (lower strength) & Concentrated load \\
\hline
\end{tabular}

The geometric properties of small scale brick-lined tunnels (see Fig. 2) were consulting database of typical ancient tunnels and from other bibliographical sources including Idris (2008). The dimension of the small scale brick-lined tunnel was relevant with a typical brick-lined tunnel with a $7 \mathrm{~m}$ diameter arch, with a scale ratio approximately equal to $1 / 10$. In order to reproduce typical brick-lined tunnels, the tunnel's brick lining consists of three layers of bricks situated at the arched region. The sidewalls, on the other hand comprise one and a half bricks juxtaposed to each other but layered alternately (see Fig. 2). For consistency this research utilised the stretcher bond as an extensively and typical used loadbearing bond, along the longitudinal direction of the entire tunnel.

Bricks used in constructing the physical models were called 'Mellowed red stock bricks', a type of traditional brick normally used for ancient brick-lined tunnels. One brick had dimensions of $107.5 \times 51.25 \times 32.5 \mathrm{~mm}(L \times W \times H)$, which was only half the size of a single Mellowed red stock brick, with dimensions of $215 \times 102.5 \times 65 \mathrm{~mm}(L \times W \times H) .5 \mathrm{~mm}$ mortar joint was consistently used to maintain the bond strength of small scale brickworks. Mortar joints less than $5 \mathrm{~mm}$ would be challenging to be made with normal sand and cement, thus would not simulate the brickworks of ancient tunnels.

A rigid support fashioned mainly from wood was utilised to support the soil surrounding the brick liner and to behave like a boundary restriction. The support was in the form of a box with the exposed faces of the second and the third ring of the brickwork tunnel covered with Perspex. After a full analysis of potential loads, deflections and factors of safety, a set of hot finished square and rectangular hollow section steel beams were designed and bolted at the front and back of the box to increase its stiffness, see Fig. 3. The dimensions of the rigid box are $2017.5 \times 332 \times 1500 \mathrm{~mm}$ $(L \times W \times H)$.

To avoid the surrounding soil slipping out of the box, the tunnel was covered with plastic sheeting all around the rigid box. Moreover, plastic sheeting played an important role in reducing the friction between the soil and the box during loading.

Portaway sand was used as the soil and compacted in layers. The surrounding soil density of $1832 \mathrm{~kg} / \mathrm{m}^{3}$ and the depth of $1075 \mathrm{~mm}$ from the tunnel toe was kept the same for all physical model tests.

The large small scale physical models are enclosed within finite boundaries provided by the rigid box, which produce more or less boundary effects. With large amount of sand surrounded the tunnel up to the boundary edge (see Fig. 4), boundary effects were

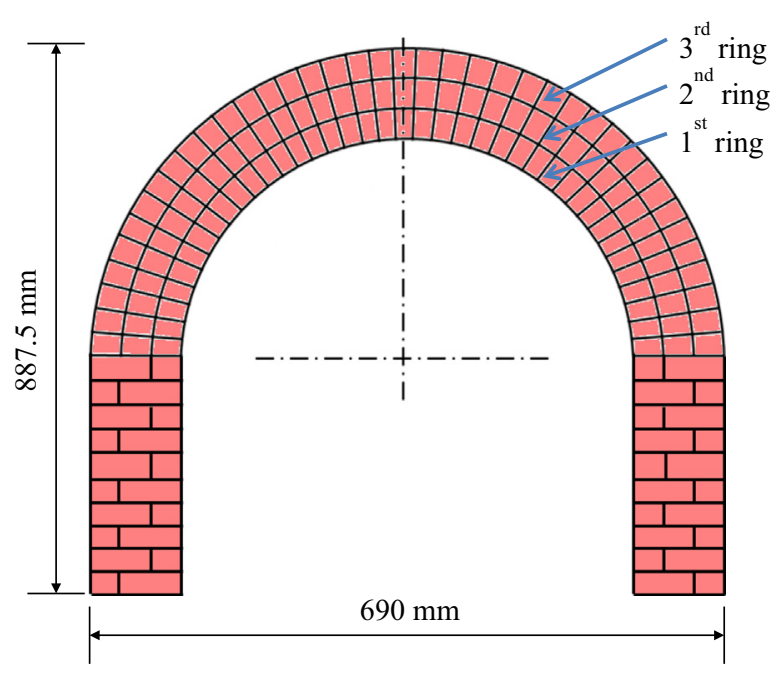

Fig. 2. Front view of the brickwork liner. 


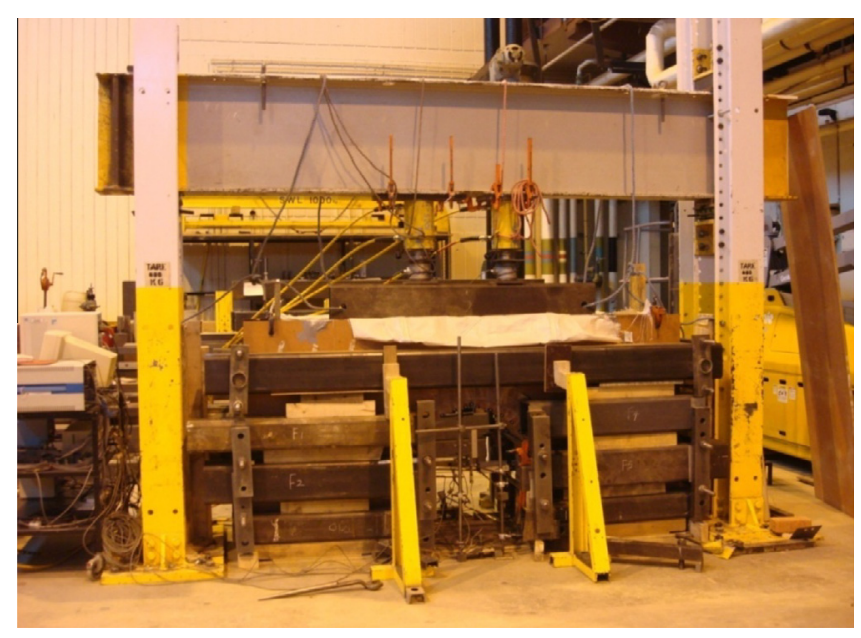

Fig. 3. Loading system installation for uniform load.

kept as less as possible. While soil behaviour close to the model edges may be affected more by boundaries; the brick-lined tunnel on the central part of the physical model is believed with only few boundary effects and can reasonably represent typical brick-lined tunnels.

In addition to the advanced measurement techniques, potentiometers were used to provide a reference for monitoring of the deformation of the tunnel.

\section{Test results of the first and the second models under uniform load}

Results from the mechanical testing of the first and second physical models were compared to ascertain the relative effects of the different mortar mix proportions used in the construction of their brick linings. The data obtained from these small scale physical model tests proved to establish qualitatively, behavioural characteristics for a typical deep seated tunnel up to failure and to determine specific tunnel failure criterion. Furthermore, the outputs of the mechanical tests acted as a benchmark for the numerical validation.

\subsection{Ultimate load capacity and tunnel mode of failure}

The first physical model with mortar mix of comparatively higher strength, failed at a load of $995 \mathrm{kN}$ when the tunnel could no longer support the load. Comparatively, the second model's ultimate load at failure was found to be $70 \%$ of that of the first model, having failed at $694 \mathrm{kN}$. Using a mortar mix of higher strength, the brickwork in the first physical model is of greater compressive strength, thus they could undertake larger stress, resulting in a greater ultimate load capacity of brick-lined tunnels as shown in Table 2. The result is also consistent with previous research by Hogg (1997).

Fig. 4 demonstrates the transmitting path of the uniform load from the steel plate on top of the overburden soil to the tunnel. In this figure, $H$ is the soil depth from the surface to the tunnel's toe, $h$ is the soil depth above the tunnel crown, $q$ is the uniformly distributed load acting on the tunnel arch and $e$ is the horizontal stress acting on the tunnel, from the top to the bottom of the tunnel (e1 to e2). By virtue of its shape, the uniformly distributed load on the arch of the tunnel caused the tunnel to act as a monolith thereby forcing the applied load to be transmitted to the sidewalls.

During the tests of both the first and the second physical models, visible cracks started from the top section of the sidewalls and spread diagonally among the sidewalls with increased uniform load, accompanied by crack noise. As the brickwork reached different ultimate compressive strength, the major structural failure in shear occurred in both the first and the second physical models, on the tunnel sidewalls, resulting in diagonal cracks among the sidewalls and excessive deformations, and finally the collapse of the tunnel. Minor tensile failure was also observed on the tunnel's crown.

\subsection{Deflection behaviour}

The observed deformation pattern of the tunnel under uniform load can be represented as shown by Fig. 5(a). It shows that it generally deforms inwards with the tunnel arch transferring the

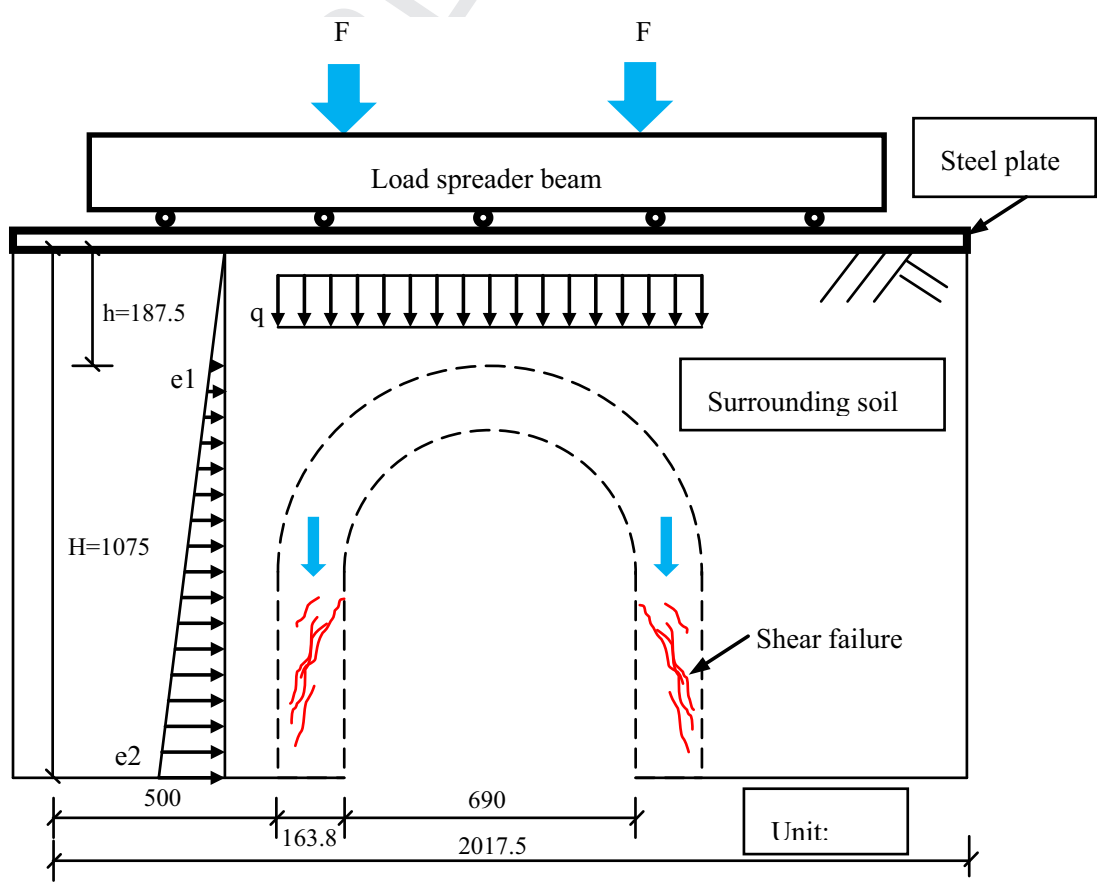

Fig. 4. Tunnel model of failure under uniform load. 
Table 2

Loading outputs from three physical models.

\begin{tabular}{|c|c|c|c|c|c|c|}
\hline $\begin{array}{l}\text { Physical } \\
\text { model }\end{array}$ & $\begin{array}{l}\text { Mortar mix } \\
\text { proportion }\end{array}$ & Loading style & $\begin{array}{l}\text { Failure load } \\
(\mathrm{kN})\end{array}$ & $\begin{array}{l}\text { Failure pressure } \\
(\mathrm{MPa})\end{array}$ & Mode of failure & Location of failure \\
\hline 1 & $\begin{array}{l}1: 1: 6 \text { (higher } \\
\text { strength) }\end{array}$ & Uniform load & 995 & 1.49 & Mainly shear failure, partially tensile failure & $\begin{array}{l}\text { Mainly tunnel sidewalls, partially } \\
\text { tunnel arch }\end{array}$ \\
\hline 2 & $\begin{array}{l}1: 2: 9 \text { (lower } \\
\text { strength) }\end{array}$ & Uniform load & 694 & 1.04 & Mainly shear failure, partially tensile failure & $\begin{array}{l}\text { Mainly tunnel sidewalls, partially } \\
\text { tunnel arch }\end{array}$ \\
\hline 3 & $\begin{array}{l}1: 2: 9 \text { (lower } \\
\text { strength) }\end{array}$ & $\begin{array}{l}\text { Concentrated } \\
\text { load }\end{array}$ & 73 & 0.73 & $\begin{array}{l}\text { Mainly five structural hinges, collapsed due } \\
\text { to ring separation }\end{array}$ & Mainly tunnel arch \\
\hline
\end{tabular}

imposed uniform load downwards to the sidewalls, resulting in a crushing phenomenon near the springing, see Fig. 5(b).

The pressure-crown deflection relationship observed from the two models is shown in Fig. 6(a) revealing similar arch structural stiffness of the two models. It suggests that the strength of mortar mix does not have significant effect on the stiffness of the bricklined tunnels. However, the first physical model test with comparatively stronger ultimate load capacity corresponded with more deformation $(62.3 \mathrm{~mm})$ at failure, while the crown displacement at failure of the second physical model test was $67.6 \%$ of that of the former test.

It is observed from Fig. 6(b) that the springing structural stiffness of the second physical model reduced to around 3/4 of that of the first physical model. It indicated that the brickwork stiffness of the second model had a great influence on the springing structural stiffness when the lateral load from the surrounding soil was parallel to the bed joints (horizontal joint in masonry). The smaller development of the springing deformation at the same load level in the first physical model test implied that the springing of the tunnel arch connected to the sidewall started to crush early than in the second physical model test, which slowed down the movement of the springing.

\subsection{Cracking behaviour}

Initial radial and stepped cracking was observed in the outwardly facing mortar joints of the first, second and third arch rings during the process of loading. These were noted to occur at $59 \%$ $(594 \mathrm{kN})$ and $56 \%(392 \mathrm{kN})$ of the total loading regime for the first and the second physical models respectively. As the loading progressed, the cracks were noted to propagate at the intrados of the tunnel arch (i.e. the inner surface of the tunnel arch). Subsequently, there was an increase in growth of radial cracking at the intrados of the tunnel arch, see Fig. 7(a).
Additionally, the onset of diagonal cracking cutting through the two tunnel sidewalls and leading to imminent shear failure was evidenced by Fig. 7(b).

\section{Test results of the third model under concentrated load}

The third physical model was subjected to concentrated loading above the centre of the tunnel crown. The mortar of the same mix proportion $(1: 2: 9)$ as the second physical model was used in the construction of the third physical model. Consequently, it was possible to compare the mechanical behaviour of tunnel structures subjected to two different load types i.e. the second physical model under uniform load and the third physical model under concentrated load.

\subsection{Ultimate capacity and tunnel mode of failure}

Fig. 8 illustrates the third physical model under concentrated load acting on the overburden soil area just above the tunnel crown, transmitted by a steel plate. During loading, the formation of structural hinges at the tunnel arch with cracking was noted at $62 \%$ of the loading programme. The third physical model experienced a sudden failure at the pressure of $0.73 \mathrm{MPa}$ which was $70 \%$ of the failure pressure of the second physical model test as shown in Table 2. The failure was due to the development of five structural hinges, point A to E shown in Fig. 9(a), this agreed with Page (1993). In addition, the collapse of partial ring sections due to ring separation of three arch rings at the tunnel crown, occurred suddenly at the maximum load as can be seen in Fig. 9(a). The ring separation normally occurs in a multi-ring masonry arch subjected to loading as shown by Casas (2011). Data result from the concentrated load test on the third physical model is shown in Table 2.
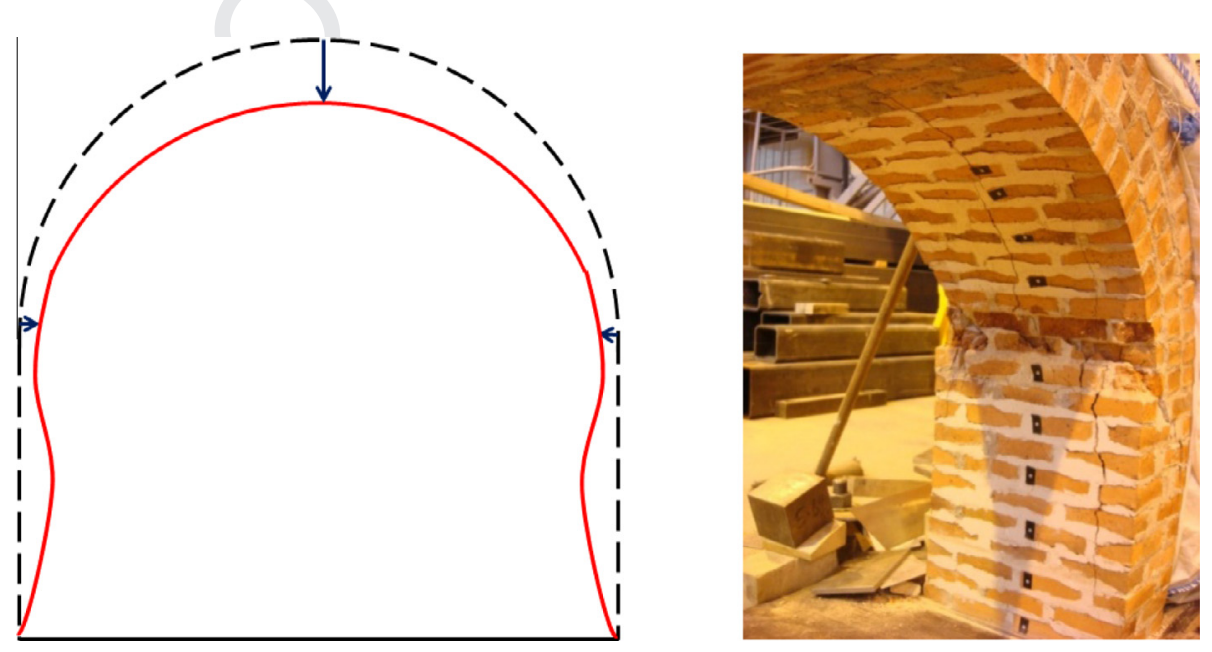

Fig. 5. (a) Deformation tendency of the tunnel; (b) crushing phenomenon at the arch springing. 

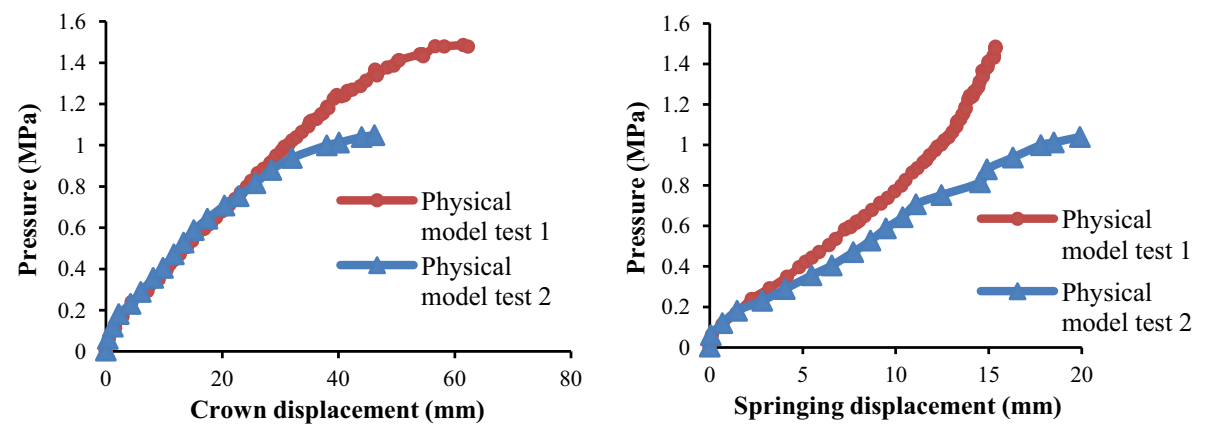

Fig. 6. (a) Pressure-crown displacement curves under uniform load; (b) pressure springing displacement curves under uniform load.
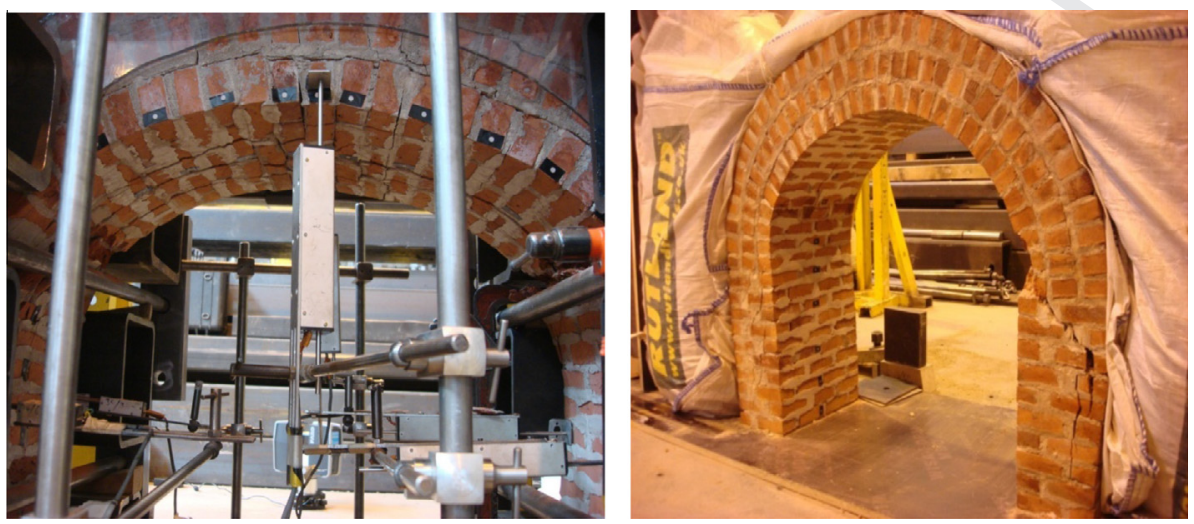

Fig. 7. (a) Crack failure under uniform load; (b) shear failure at sidewalls.

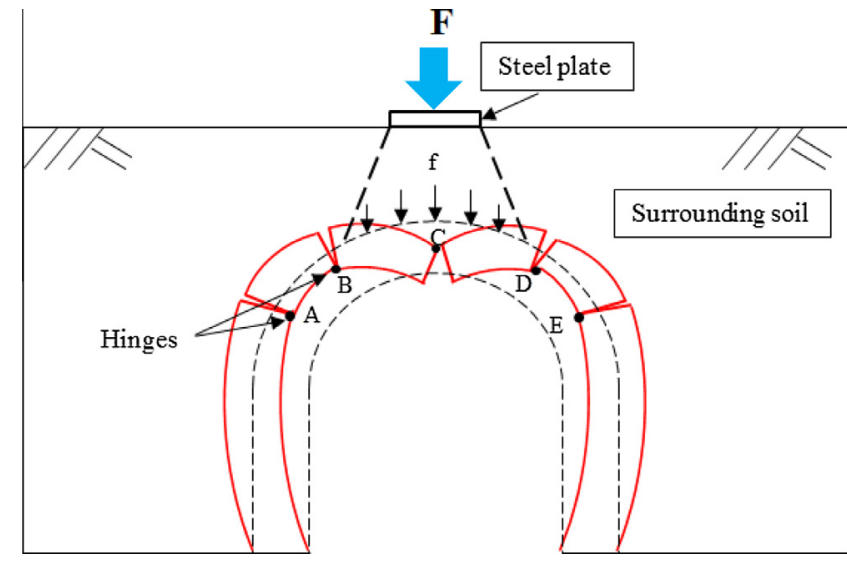

Fig. 8. Tunnel model of failure under concentrated load.

\subsection{Deflection and cracking behaviour}

A simplistic depiction of the deformation tendency to failure is shown in Fig. 9(b) where the sidewalls deformed outwards from the tunnel profile and the crown at the third ring deformed inwards over the loading period.

For the same mortar mix ratio (1:2:9), the third physical model was placed under concentrated load where it experienced only half vertical movement of the crown at failure, compared to that of the second physical model under uniform load as shown in Fig. 10(a). In the third physical model, the tunnel crown at the first (inner) arch ring recorded diagonal deformation, developing a structural hinge at the third (outer) arch ring and cracks through three arch rings at the tunnel crown. In the second physical model, the tunnel crown only moved vertically. With regards to springing deflection at failure, the third physical model had comparable springing displacement within $5 \%$ difference from that of the second physical model as can be seen in Fig. 10(b).

\section{Numerical simulation}

\subsection{General introduction}

Numerical models were developed using FLAC (Finite Difference Method) and UDEC (Distinct Element Method) programmes and used to simulate and compare the mechanical behaviour of the corresponding physical models after loading. This would then allow these numerical models to be applied to future field studies to enable accurate predictions of the actual mechanical behaviour of a masonry tunnel.

In FLAC, the macro-modelling strategy (Idris et al., 2008) was used, which was to consider the brick, mortar and brick/mortar interface smeared out in a homogeneous anisotropic continuum; while the simplified micro-modelling strategy (Idris et al., 2008) was applied to UDEC which assumed the continuum part of detailed micro-modelling expands to zero thickness interfaces.

\subsection{Parametric study}

A series of experimental tests were carried out to obtain the material properties of brick, brickwork, mortar and soil used in three physical models (Young's modulus, friction angle, cohesion, etc.). The tests included uni-axial and single stage tri-axial compressive strength tests, direct shear box tests, density tests and tensile/shear strength tests.

Table 3 lists the mechanical properties assigned to brickwork (block) with mortar mix proportion of 1:1:6 and interface of 


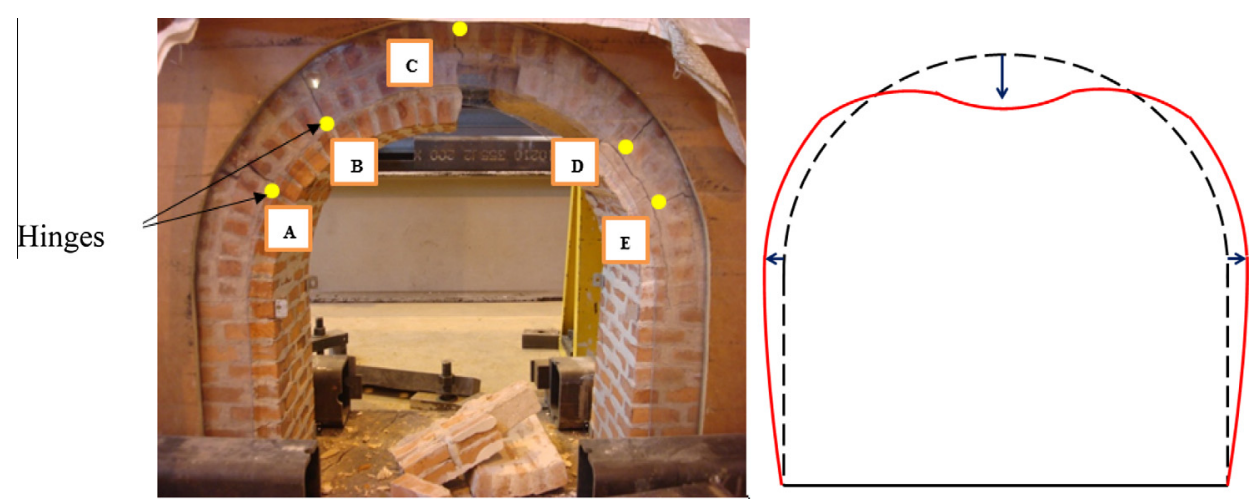

Fig. 9. (a) Collapse during the physical model test under concentrated load; (b) deformation tendency of the tunnel profile under concentrated load.
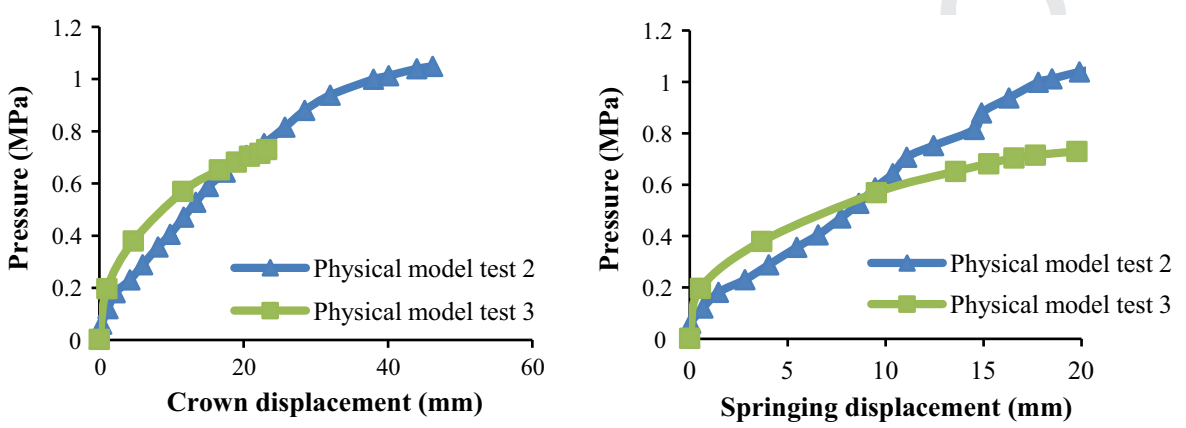

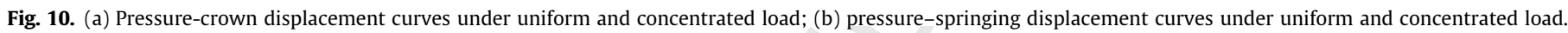

brickwork and soil, as the material properties of a baseline model for both FLAC and UDEC modelling. These properties are from experimental tests, analytical solutions and some estimation such as joint friction and joint cohesion. The brickwork block joint properties are assigned to UDEC models only. The properties of surrounding soil were always kept the same during the whole process of numerical simulation, based on the laboratory tests.

Take the first physical model under uniform load for example, the stiffness and strength properties of the brickwork and the brickwork/soil joint were selected for the parametric study in FLAC and UDEC modelling, e.g. Poisson's ratio $(v)$, Young's modulus $(E)$, cohesion $(c)$, friction angle $(\varphi)$, joint normal and shear stiffness

Table 3

Surrounding soil, brickwork (mix proportion 1:1:6), brickwork/soil joint and brickwork block joint properties.

\begin{tabular}{|c|c|c|c|c|c|}
\hline \multicolumn{6}{|c|}{ Surrounding soil } \\
\hline$\rho\left(\mathrm{kg} / \mathrm{m}^{3}\right)$ & $E(\mathrm{MPa})$ & $v$ & $c(\mathrm{MPa})$ & $\varphi$ & $\operatorname{Tr}(\mathrm{MPa})$ \\
\hline 1832 & $26^{* 1}$ & $0.3^{* 1}$ & 0 & $44^{\circ}$ & $0 * 1$ \\
\hline \multicolumn{6}{|c|}{ Brickwork (block ${ }^{* 2}$ ) $(1: 1: 6)$} \\
\hline$\rho\left(\mathrm{kg} / \mathrm{m}^{3}\right)$ & $E(\mathrm{MPa})$ & $v$ & $c(\mathrm{MPa})$ & $\varphi$ & $\operatorname{Tr}(\mathrm{MPa})$ \\
\hline 1732 & 384.33 & $0.2^{* 1}$ & 0.1845 & $55^{\circ}$ & $0.2437^{* 1}$ \\
\hline \multicolumn{6}{|c|}{ Brickwork/soil joint } \\
\hline & $\mathrm{JKn}_{1}(\mathrm{GPa} / \mathrm{m})$ & $\mathrm{JKs}_{1}(\mathrm{GPa} / \mathrm{m})$ & $\mathrm{Jc}_{1}(\mathrm{MPa})$ & $J \varphi_{1}$ & $\mathrm{JTr}_{1}(\mathrm{MPa})$ \\
\hline & 112.97 & 112.97 & 0 & $25^{* 1}$ & 0 \\
\hline \multicolumn{6}{|c|}{ Brickwork block $^{* 2}$ joint } \\
\hline & $\mathrm{JKn}_{2}(\mathrm{GPa} / \mathrm{m})$ & $\mathrm{JKs}_{2}(\mathrm{GPa} / \mathrm{m})$ & $\mathrm{Jc}_{2}(\mathrm{MPa})$ & $J \varphi_{2}$ & $\mathrm{JTr}_{2}(\mathrm{MPa})$ \\
\hline & 112.97 & 112.97 & 0.1521 & $25^{* 1}$ & 0.218 \\
\hline
\end{tabular}

${ }^{* 1}$ Young's modulus and Poisson's ratio of the surrounding soil are referring to Juspi (2007); Poisson's ratio of the brickwork and the friction angle of the joint $\left(J \varphi_{1}, J \varphi_{2}\right)$ are referring to Idris et al. (2008); $\mathrm{Tr}$ is the tensile strength of the surrounding soil and brickwork.

${ }^{* 2}$ Brickwork block is only simulated in UDEC models.
(JKn, JKs), and joint friction angle $(J \varphi)$. For $v, E, c$ and $\varphi$, the parametric variations were the range of the maximum and minimum values of each factor, based on the laboratory test; For JKn, JKs, and $J \varphi$, the variations were based on empirical estimation.

A comprehensive parametric design was proposed with corresponding experiments as shown in Tables 4-7. Every experiment was numerically simulated to investigate the effects of these properties on masonry structure behaviour. The response factor selected is the crown displacement trend of the model until failure.

FLAC model A7 (see Table 5 for details) was proved to be the one to simulate the physical model 1 , since its performance i.e. deformation and failure characteristics under loading was very similar to the physical model test 1 . The stiffness properties of brickwork FLAC model A7 was directly obtained from experimental tests which was as the same as that of the physical model 1 ; while the strength properties varied slightly (see Tables 4 and 5). The cohesion of the brickwork was reduced by $13 \%$ in FLAC model A7; the friction angle of the brickwork was reduced by $9 \%$ in FLAC model A7 to best fit the physical model 1 .

UDEC model A3 (see Table 7 for details) was also proved to be the best one to simulate the physical model 1, with the same values of brickwork block parameters as brickwork parameters of FLAC model A7.

Table 4

Brickwork parametric study of Poisson's ratio, Young's modulus and friction angle (mix proportion of 1:1:6).

\begin{tabular}{lllllll}
\hline & $E(\mathrm{MPa})$ & $v$ & $c(\mathrm{MPa})$ & $\varphi\left(^{\circ}\right)$ & $\mathrm{JKn}_{1}=\mathrm{JKs}_{1}(\mathrm{GPa} / \mathrm{m})$ & $J \varphi_{1}\left(^{\circ}\right)$ \\
\hline Baseline A & 384.33 & 0.2 & 0.1845 & 55 & 112.97 & 25 \\
FLAC A1 & 384.33 & 0.3 & 0.1845 & 55 & 112.97 & 25 \\
FLAC A2 & 553 & 0.2 & 0.1845 & 55 & 112.97 & 25 \\
FLAC A3 & 249 & 0.2 & 0.1845 & 55 & 112.97 & 25 \\
FLAC A4 & 384.33 & 0.2 & 0.1845 & 50 & 112.97 & 25 \\
FLAC A5 & 384.33 & 0.2 & 0.1845 & 52 & 112.97 & 25
\end{tabular}


Table 5

Parametric study of the brickwork cohesion (1:1:6).

\begin{tabular}{lllllll}
\hline & $E(\mathrm{MPa})$ & $v$ & $c(\mathrm{MPa})$ & $\varphi\left({ }^{\circ}\right)$ & $\mathrm{JKn}_{1}=\mathrm{JKs}_{1}(\mathrm{GPa} / \mathrm{m})$ & $J \varphi_{1}\left({ }^{\circ}\right)$ \\
\hline FLAC A4 & 384.33 & 0.2 & 0.1845 & 50 & 112.97 & 25 \\
FLAC A6 & 384.33 & 0.2 & 0.2 & 50 & 112.97 & 25 \\
FLAC A7 & 384.33 & 0.2 & 0.16 & 50 & 112.97 & 25 \\
FLAC A8 & 384.33 & 0.2 & 0.14 & 50 & 112.97 & 25 \\
\hline
\end{tabular}

Table 6

Parametric study of brickwork Young's modulus, joint friction angle and stiffness $(1: 1: 6)$.

\begin{tabular}{lllllll}
\hline & $E(\mathrm{MPa})$ & $v$ & $c(\mathrm{MPa})$ & $\varphi\left({ }^{\circ}\right)$ & $\mathrm{JKn}_{1}=\mathrm{JKs}_{1}(\mathrm{GPa} / \mathrm{m})$ & $J \varphi_{1}\left({ }^{\circ}\right)$ \\
\hline FLAC A7 & 384.33 & 0.2 & 0.16 & 50 & 112.97 & 25 \\
FLAC A9 & 384.33 & 0.2 & 0.16 & 50 & 112.97 & 30 \\
FLAC A10 & 384.33 & 0.2 & 0.16 & 50 & 112.97 & 35 \\
FLAC A11 & 384.33 & 0.2 & 0.16 & 50 & 112.97 & 40 \\
FLAC A12 & 553 & 0.2 & 0.16 & 50 & 162.55 & 25 \\
FLAC A13 & 249 & 0.2 & 0.16 & 50 & 73.19 & 25 \\
FLAC A14 & 384.33 & 0.2 & 0.16 & 50 & 56.49 & 25 \\
\hline
\end{tabular}

Table 7

Parametric study of the brickwork block cohesion and joint stiffness.

\begin{tabular}{llllllll}
\hline & $E(\mathrm{MPa})$ & $v$ & $c(\mathrm{MPa})$ & $\varphi\left(^{\circ}\right)$ & $\begin{array}{l}\mathrm{JKs}_{2} \\
(\mathrm{GPa} / \mathrm{m})\end{array}$ & $\begin{array}{l}\mathrm{JKn}_{2} \\
(\mathrm{GPa} / \mathrm{m})\end{array}$ & $J \varphi_{2}\left(^{\circ}\right)$ \\
\hline Baseline A & 384.33 & 0.2 & 0.1845 & 55 & 112.97 & 112.97 & 25 \\
UDEC A1 & 384.33 & 0.2 & 0.1845 & 50 & 112.97 & 112.97 & 25 \\
UDEC A2 & 384.33 & 0.2 & 0.1845 & 52 & 112.97 & 112.97 & 25 \\
UDEC A3 & 384.33 & 0.2 & 0.16 & 50 & 112.97 & 112.97 & 25 \\
UDEC A4 & 384.33 & 0.2 & 0.16 & 50 & 28.83 & 69.18 & 25 \\
\hline
\end{tabular}

The decrease in friction angle of the brickwork increased the crown displacement up to $75 \%$ of the FLAC baseline A; the variation of cohesion of the brickwork significantly affects the ultimate load and the stiffness of the brick-lined tunnel. The increase in joint friction angle slightly changed the crown displacement curve.

The results of the parametric study indicate that both friction angle and cohesion the brickwork have a significant influence on the brick-lined tunnel mechanical behaviour with the most important parameter being cohesion. It shows a good agreement with Idris et al. (2008) on the property study of masonry blocks.

The rest of the factors considered (Poisson's ratio, Young's modulus of the brickwork, joint stiffness and friction angle) do not have a significant influence on the mechanical behaviour of the bricklined tunnel.

\subsection{Comparison with physical model tests}

Numerical modelling results using both FLAC and UDEC software were analysed and compared with physical model tests of brick-lined tunnels, as shown in Figs. 11 and 12. Take the FLAC numerical model simulating the first physical model for example, the deformation tendency in the numerical modelling shows that the tunnel deforms inwards, being squeezed and bent all over (see Fig. 13). The status of the numerical model changed from elastic to plastic behaviour under uniform load, yielding in shear at sidewalls (see Fig. 14). Both numerical modelling results are coincident with the results of the physical model test (shown in the lower left-hand corner of Fig. 14), with a similar deformation trend and shear failure at the tunnel sides. Thus, it proves that, the numerical models can be effectively used in the study of the mechanical behaviour of masonry tunnel and its stability.

These good agreements with physical model tests $1-3$ encouraged further predictions of performance using numerical modelling under various conditions, and will be discussed in Section 7.

\section{Prediction of numerical simulations}

\subsection{Introduction}

Based on the previous numerical modelling, the deformation characteristics, mechanical behaviour and probable failure mechanisms of the brick-lined tunnels under different conditions are predicted by FLAC and UDEC software separately.

\subsection{Overburden soil depth}

In order to figure out the interaction of the overburden soil on brick-lined tunnels, various soil depths (from the tunnel bottom, toe) are used in numerical models. Depths from $980 \mathrm{~mm}$ to

(b)

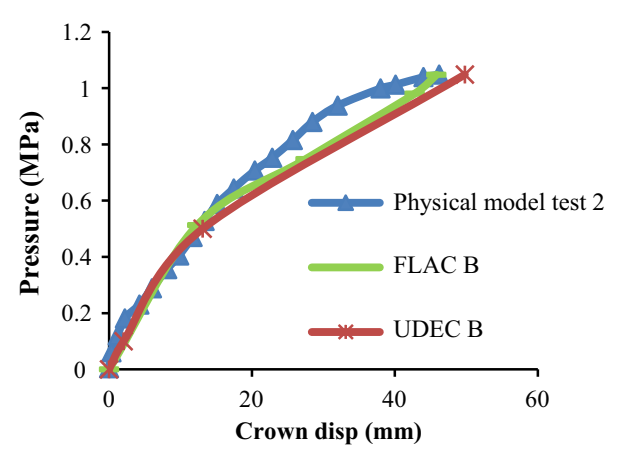

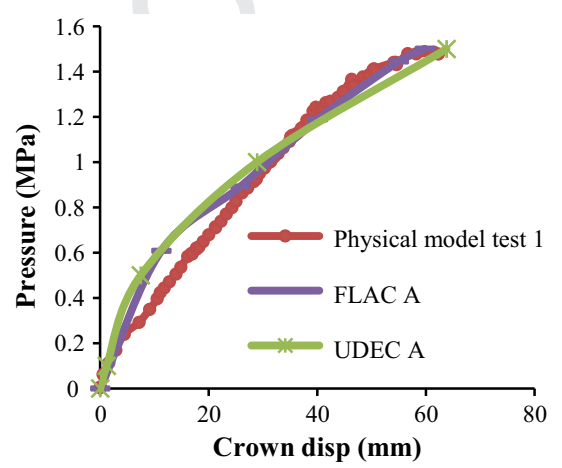

(a)

Fig. 11. Physical model test 1 (a) \& physical model test 2, (b) vs. numerical curves 


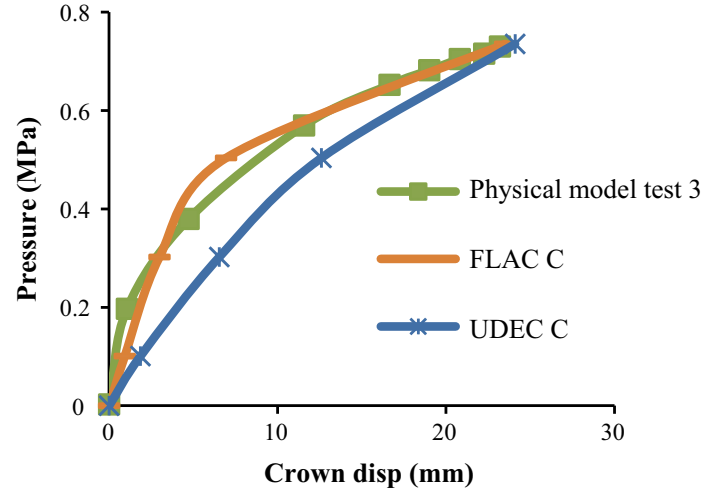

Fig. 12. Physical model test 3 vs. numerical curves.

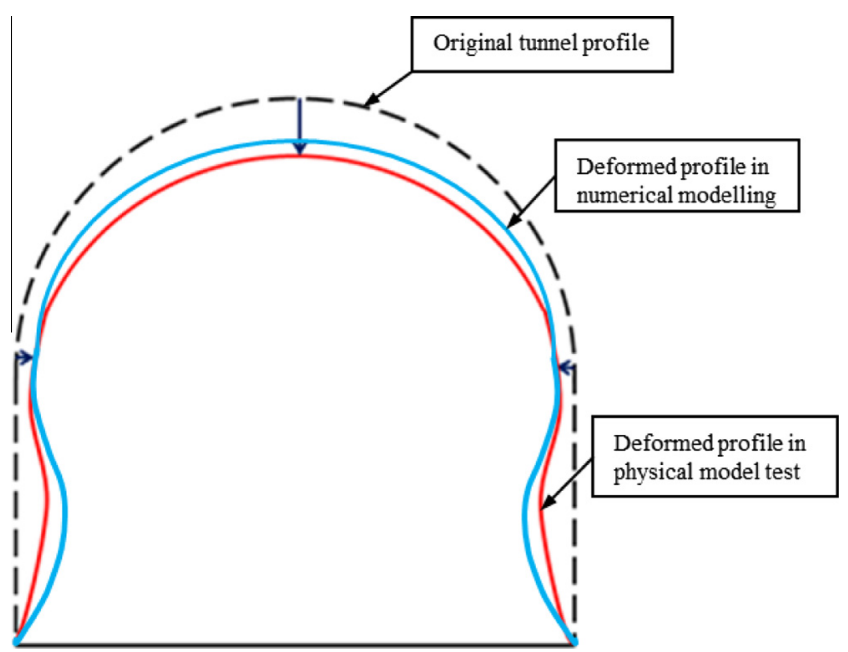

Fig. 13. Deformation tendency of numerical model $(1: 1: 6)$ during uniform static load compared with the physical model.
$1455 \mathrm{~mm}$ in increments of $95 \mathrm{~mm}$ or $190 \mathrm{~mm}$ were added each time, as can be seen in Table 7 .

For the model under uniform load, the increase in soil depth gradually decreases the overall stiffness and failure load of the brick-lined tunnel, as can be seen in Fig. 15(a). Fig. 16 clearly shows that the brick-lined tunnel will fail due to shear failure not only occurring at the tunnel sidewalls, but also extending largely to the tunnel arch as the soil depth rises.

On the contrary, for the model under concentrated load, an increase in the soil depth leads to an increase in the overall stiffness of the brick-lined tunnel dramatically, as can be seen in Fig. 15(b). As Fig. 17 shows, a brick-lined tunnel with a soil depth beyond $1265 \mathrm{~mm}$ can sustain a heavier concentrated load. Since the thicker soil layer above the tunnel makes the concentrated load with good dispersion (see Table 8).

\subsection{Concentrated load}

In order to simulate the overloading and failure of 'Brickwork Bridge' due to heavy vehicles, numerical models are then developed to study the failure mechanism of the brick-lined tunnels under concentrated load at different locations.

The performance of numerical modelling under concentrated load at different positions is predicted as followed, especially at one quarter across the tunnel arch and at the middle of the tunnel arch which are usually considered to be the critical loading position (Robinson and Kapoor, 2009). With the load $0.1 \mathrm{~m}$ wide, the UDEC modelling was used to predict better local mechanical behaviour.

As an application of 'Brickwork Bridge' under a pavement, Fig. 18 demonstrates the failure pattern and deformation of the UDEC model under concentrated load at 1/4 way across the tunnel arch. Compared to the concentrated load at $1 / 2$ way across the arch with direct tensile failure at the crown as shown in Fig. 19, the load at 1/4 way across the arch has been transferred to one side of the tunnel arch. The failure load is larger with tensile failure at one side of the arch.

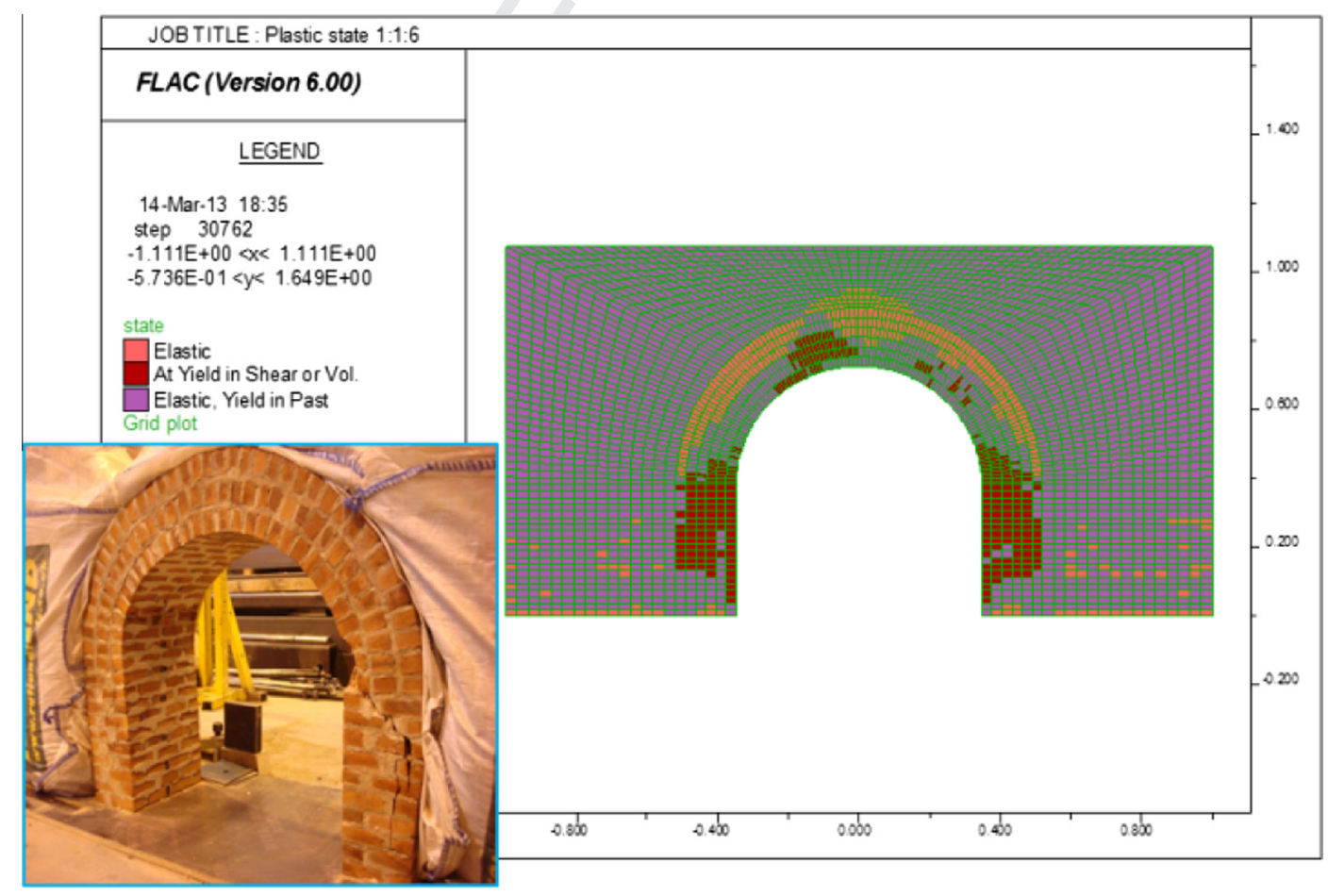

Fig. 14. Plastic state of numerical model (1:1:6) compared with the physical model. 


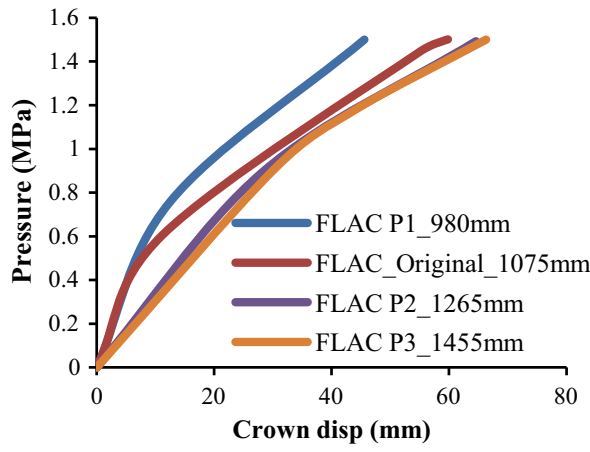

(a)

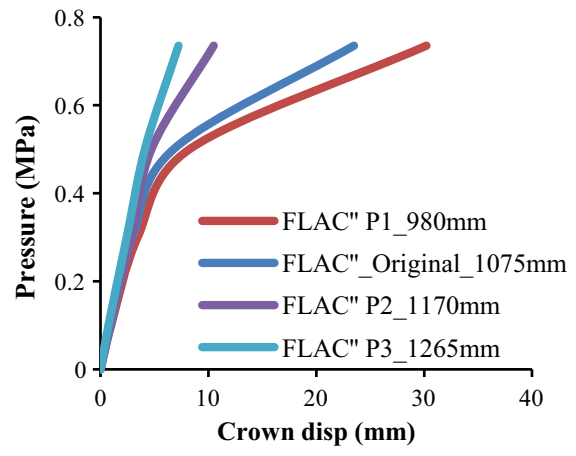

(b)

Fig. 15. Prediction of crown displacement curves under (a) uniform load and (b) concentrated load.

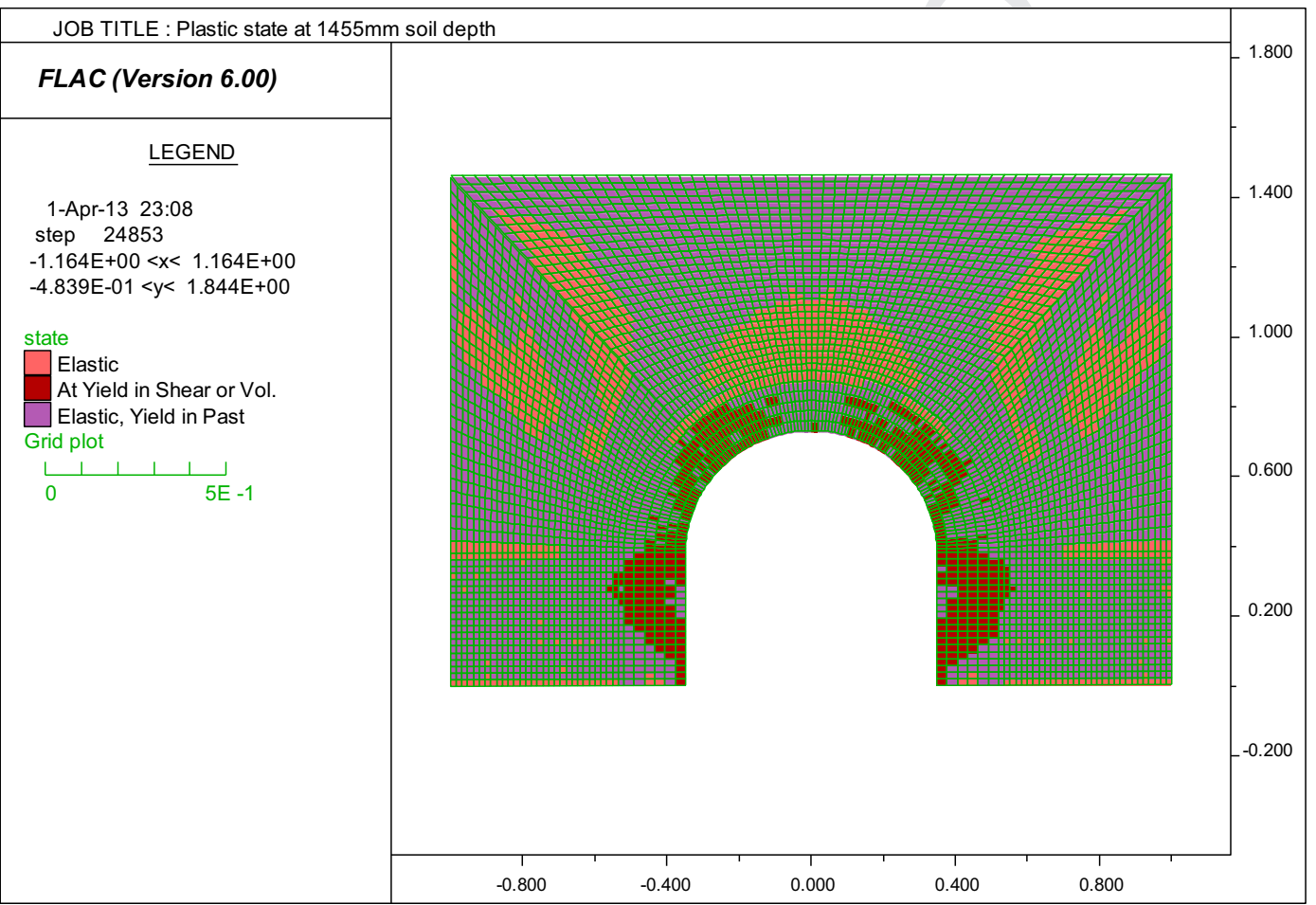

Fig. 16. Plastic state of FLAC model (1:1:6) under uniform load at $1455 \mathrm{~mm}$.

Table 8

Prediction of numerical models under uniform and concentrated load.

\begin{tabular}{|c|c|c|c|c|}
\hline $\begin{array}{l}\text { Numerical } \\
\text { model No. }\end{array}$ & $\begin{array}{l}\text { Overburden } \\
\text { soil depth } \\
(\mathrm{mm})\end{array}$ & $\begin{array}{l}\text { Depth } \\
\text { difference } \\
(\mathrm{mm})\end{array}$ & Loading style & $\begin{array}{l}\text { Mortar mix } \\
\text { proportion }\end{array}$ \\
\hline 1 & 980 & & Uniform load & $\begin{array}{l}1: 1: 6 \\
\text { (higher } \\
\text { strength) }\end{array}$ \\
\hline 2 & 1075 & 95 & & \\
\hline 3 & 1265 & 190 & & \\
\hline 4 & 1455 & 190 & & \\
\hline 7 & 980 & & $\begin{array}{l}\text { Concentrated } \\
\text { load }\end{array}$ & $\begin{array}{l}1: 2: 9 \\
\text { (weaker } \\
\text { strength) }\end{array}$ \\
\hline 8 & 1075 & 95 & & \\
\hline 9 & 1170 & 95 & & \\
\hline 10 & 1265 & 95 & & \\
\hline
\end{tabular}

\section{Conclusion}

The test results from physical scale models clearly indicated the mechanical behaviour of the brick-lined tunnels, e.g. deflection pattern of brick lining, force-displacement relationship, crack formation and failure mechanism. The failure pattern of physical models under uniform and concentrated load differed. The first two physical models, which were under uniform load, failed as a result of shear failure at the sidewalls as the major force was transferred to the sides. The third physical model, which was under concentrated load, failed due to the formation of five structural hinges at the tunnel arch. The strength of mortar has a large influence on the overall behaviour. The model test under concentrated load showed more brittle behaviour than under uniform load.

Numerical simulations were presented with continuum and discontinuum methods. Quantitative agreement with the physical 


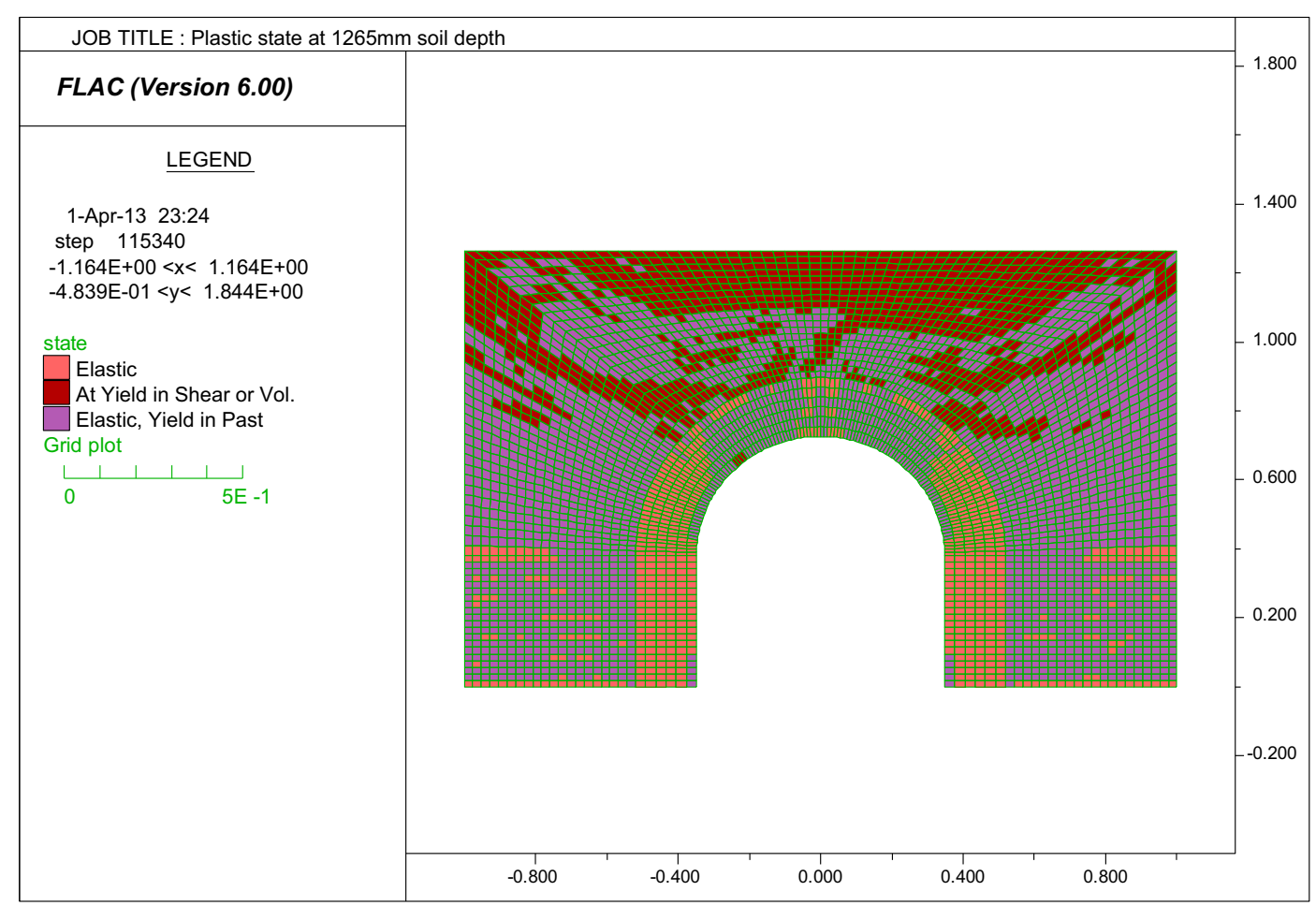

Fig. 17. Plastic state of FLAC model (1:2:9) under concentrated load at $1265 \mathrm{~mm}$ soil depth.

tests was achieved from parameter studies. The deflection and failure mechanism could be reasonably simulated. Results from the parametric analysis confirmed that, in both numerical methods, the cohesion of brickwork (blocks in UDEC) was the dominant factor, followed by the friction angle of brickwork. These results agreed with the findings of Idris et al. (2008). However, numerical models were not very sensitive to the Poisson's ratio, Young's modulus of the brickwork, joint stiffness, joint cohesion or the joint friction angle. Generally, the micro-modelling strategy (used in UDEC) shows a better agreement with the physical model test of the local failure behaviour of brickwork structures. The failure pattern of the UDEC model under concentrated load clearly demonstrates the hinges and cracks at certain positions of the tunnel arch. The macro-modelling strategy applied in FLAC simulates reasonably well the deformation characteristics and shows a good agreement with the three physical model tests.

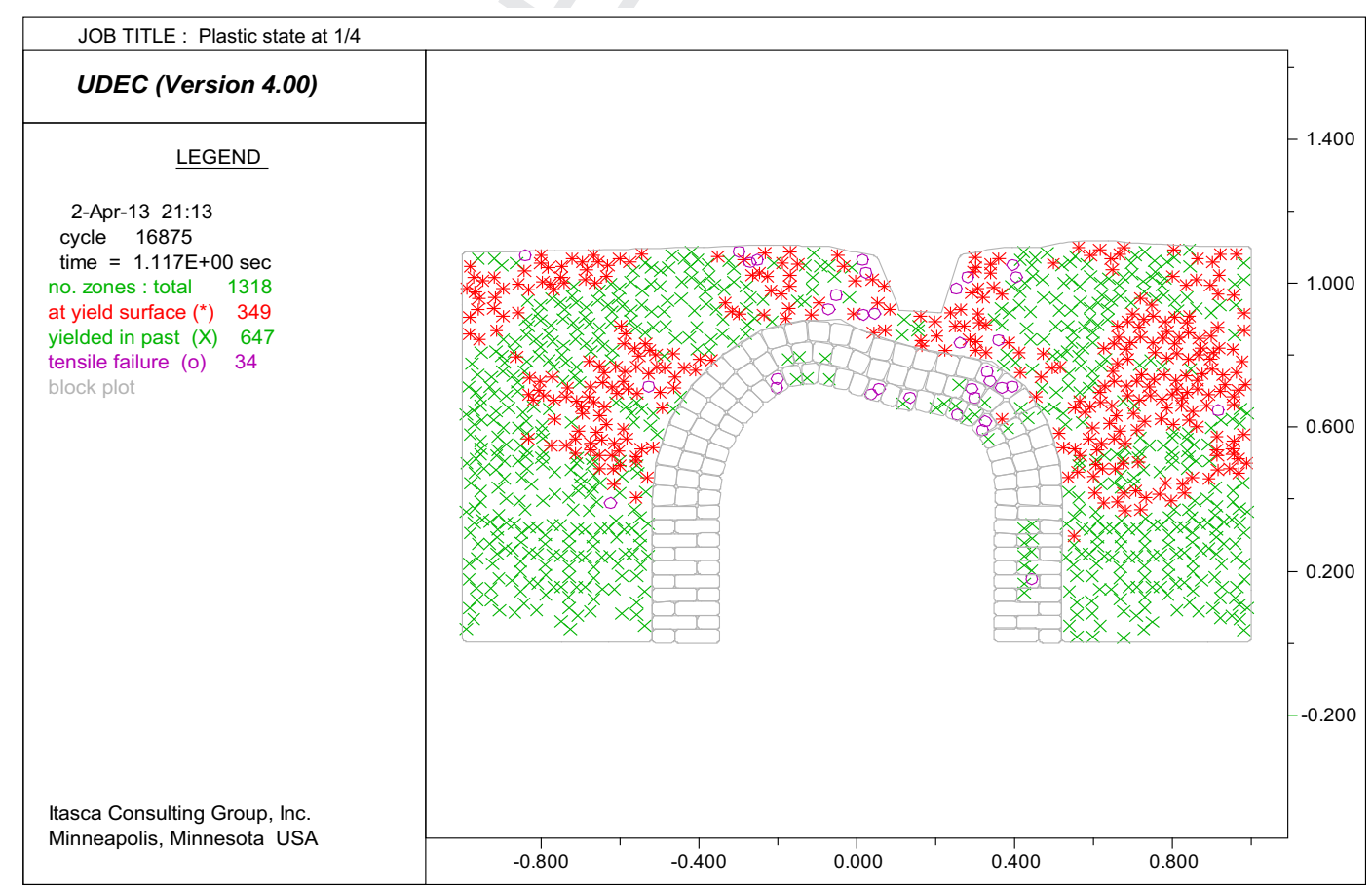

Fig. 18. Prediction of plastic state under concentrated load at $1 / 4$ of the arch. 


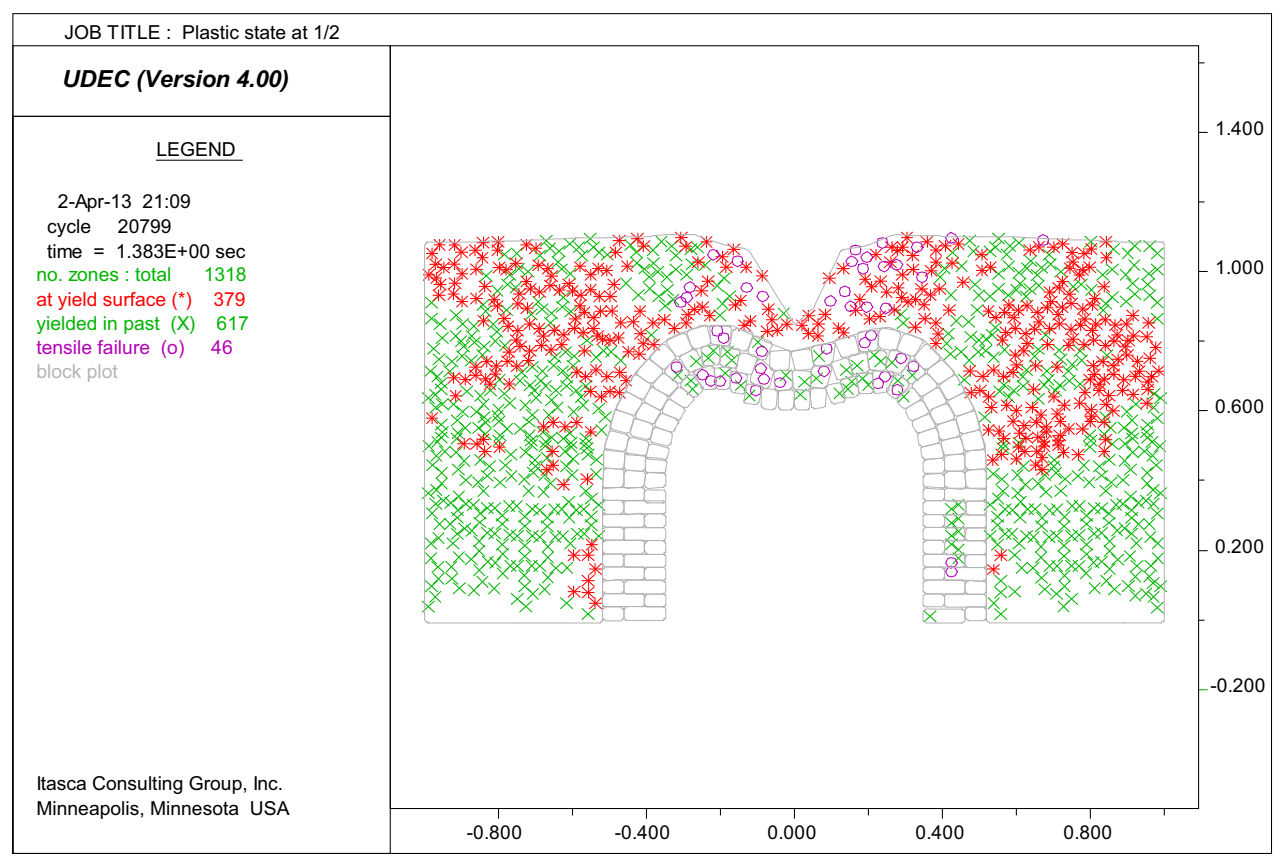

Fig. 19. Prediction of plastic state under concentrated load at $1 / 2$ of the arch.

Prediction of numerical models at various soil depths under uniform load showed the interaction between a brick-lined tunnel and the overburdened soil; prediction at different locations under concentrated load was linked to the engineering application of a 'Brickwork Bridge' under a pavement. It was shown that, under uniform load, shear failure not only occurred at the tunnel sidewalls, but also extended to the tunnel arch. As the soil depth increased, the concentrated load at the middle of the arch failed easier due to direct tensile failure at the crown, compared to the load one quarter across the arch.

As a recommendation for further modelling work, it would be interesting to introduce other constitutive models related to masonry structures to simulate the longer term deformation and stress conditions of brick-lined tunnels after years of degradation. More realistic conditions could be applied, such as tunnels surrounded by anisotropic geotechnical materials and cyclic loading, representing moving vehicles on the road.

\section{Acknowledgements}

The research was conducted while Dr. Han-Mei Chen was studying at The University of Nottingham towards a PhD. The authors are grateful to all technicians working in the Nottingham Centre for Geomechanics and the laboratory of Civil Engineering for providing their assistance throughout the experimental work, and to the staff from Nottingham Geospatial Institute especially Dr. Nikolaos Kokkas for providing advice on this research.

\section{References}

Betti, M., Drosopoulos, G.A., Stavroulakis, G.E., 2008. Two non-linear finite element models developed for the assessment of failure of masonry arches. Comptes Rendus Mécanique 336 (1-2), 42-53.
BS 4551:1980, 1980. Methods of Testing Mortars, Screeds and Plasters. British Standards Institution, London.

Casas, J.R., 2011. Reliability-based assessment of masonry arch bridges. Constr. Build. Mater. 25 (4), 1621-1631.

Chen, H.-M., Yu, H.-S., Smith, M.J., Kokkas, N., 2013. Advanced monitoring techniques for assessing the stability of small-scale tunnels. In: 2nd Joint International Symposium on Deformation Monitoring (JISDM), The University of Nottingham on 9-11 September 2013.

Chen, H.-M., 2014. Physical Model Tests and Numerical Simulation for Assessing the Stability of Tunnels. PhD Thesis, Faculty of Engineering, University of Nottingham, UK.

Chen, H.-M., Smith, M.J., Yu, H.-S., Kokkas, N., 2014. Monitoring the deformation of small scale model tunnels under load testing. Surv. Rev. 46 (339), 417-425.

Giordano, A., Mele, E., de Luca, A., 2002. Modelling of historical masonry structures: comparison of different approaches through a case study. Eng. Struct. 24, 10571069.

Hogg, V., 1997. Effects of Repeated Loading on Masonry Arch Bridges and Implications for the Serviceability Limit State. PhD Thesis, Department of Civil Engineering, University of Nottingham.

Idris, J., Verdel, T., Al-Heib, M., 2008. Numerical modelling and mechanical behaviour analysis of ancient tunnel masonry structures. Tunn. Undergr. Space Technol. 23, 251-263.

Idris, J., Al-Heib, M., Verdel, T., 2009. Numerical modelling of masonry joints degradation in built tunnels. Tunn. Undergr. Space Technol. 24, 617-626.

Juspi, S., 2007. Experimental Validation of the Shakedown Concept for Pavement Analysis and Design. PhD Thesis, Department of Civil Engineering, University of Nottingham.

Lourenço, P.B., 1996. Computational Strategies for Masonry Structures. PhD Thesis, Department of Civil Engineering, Delft University of Technology.

Lourenço, P.B., 1998. Experimental and numerical issues in the modelling of the mechanical behaviour of masonry. In: Roca, P., González, J.L., Oñate, E., Lourenco, P.B. (Eds.), Structural Analysis of Historical Constructions II. Possibilities of Numerical and Experimental Techniques. CIMNE, pp. 57-92.

Page, J., 1993. State-of-the-art-review: Masonry Arch Bridges. Transport Research Laboratory, HMSO publications.

Robinson, A.M., Kapoor, A. (Eds.), 2009. Fatigue in Railway Infrastructure. Woodhead Publishing.

Sutcliffe, D.J., 2003. Masonry Shear Walls: a Limit Analysis Approach. PhD Thesis, Discipline of Civil, Surveying and Environmental Engineering, University of Newcastle, Australia.

Valluzzi, M.R., Binda, L., Modena, C., 2005. Mechanical behaviour of historic masonry structures strengthened by bed joints structural repointing. Constr. Build. Mater. 19, 63-73. 